\title{
The effects of added transportation capacity on travel: a review of theoretical and empirical results
}

\author{
Ryuichi Kitamura
}

Published online: 26 January 2010

(C) Federal Highway Administration 1994

\begin{abstract}
The addition of transportation capacity affects potentially all attributes of trips made by urban residents: time of day, destination, mode, route, and linking of trips. In the long run, added capacity may influence a household's automobile ownership decision, residence, and job location choice, as well as firms' location decisions. Neither primary growth effects nor the secondary trip effects of added capacity are thoroughly understood-determining the effect of added capacity is not at all a trivial task because it is concerned with intricately and dynamically interrelated system components: transportation supply system, land use, accessibility, and travel demand. This paper presents a review of theoretical and empirical results in the literature that shed light on the effect of added transportation capacity. Tentative findings include the following: Using existing origin-destination data appears to be a very cost-effective and expeditious approach to addressing the added capacity issue, but it can be better used with more elaborate statistical methods to test behavioral theories. There is no empirical indication that added capacity generates a significant volume of induced traffic. The standard sequential procedure is capable, in principle, of forecasting diverted, transferred, and shifted traffic, although actual practice may be less than ideal. Abbreviated application of the procedure, unwarranted attempts to transfer models and extrapolation of the models to inapplicable options are unfortunately present. A better understanding of trip timing decisions and trip chaining behavior is needed. Impacts on car ownership, residential and job location choice, and land use need to be better understood and incorporated into the forecasting procedure. More widespread use of panel surveys is encouraged.
\end{abstract}

KEYWORDS Induced demand · Latent demand · Capacity enhancements ·

Travel demand forecasting

Originally appeared as, the effects of added transportation capacity on travel: A review of theoretical and empirical results. In Gordon.A. Shunk (ed.), The Effects of Added Transportation Capacity, DOT-T-94-12, U.S. Department of Transportation, Washington, D.C., 1994, pp. 79-95.

R. Kitamura

University of California, Davis, CA, USA 


\section{INTRODUCTION}

The addition of transportation capacity affects potentially all attributes of trips made by urban residents; i.e., time of day, destination, mode, route, and linking of trips. The impact could be more pronounced if unsatisfied or latent demand exists due to congestion (Cambridge Systematics, Inc., and JHK \& Associates 1979). In the long run, added capacity may influence a household's automobile ownership decision, residence, and job location choice. Firms' location decisions will also be affected. Sooner or later, waves of development start filling the fringe area. It appears most certain that as long as the urban area continues to grow, fringe land with good transportation access will be converted to residential and commercial use. The addition of transportation capacity is one of the key contributors to urban growth. ${ }^{1}$

Perhaps the most fundamental impact of added capacity is attributable to urban growth stemming from the ability of transportation capacity to support a larger urban population and more extensive non-residential activities. Obviously, this growth has immediate impact on travel demand: an X percent increase in an area's work force would probably lead to an increase in work trip generation by approximately $\mathrm{X}$ percent. Possible increases due to changes in departure times, destinations, modes, routes, or even induced trips, appear minute when compared with this primary growth effect.

However, if growth were controlled by strict land-use measures or if growth in an urban area were supported by its political constituencies, then the secondary impacts of added capacity would no longer be a trivial issue. One would need to address the questions: What is the trip-inducing effect of added capacity? If highways were not congested, would people go out more often and drive farther? One may also be concerned with the long-term effects of added capacity upon the evolution of an urban area. Would people own fewer automobiles and use public transit more if the capacity of the transit system increased? Would radial expansion of the highway system merely contribute to ever-increasing trip lengths?

Neither primary growth effects nor the secondary trip effects of added capacity are thoroughly understood. The growth effects are not incorporated into the standard urban passenger travel demand forecasting procedure in the sense that future land use is predetermined, essentially independent of the future travel demand and supply. Nor are the effects of improved accessibility on trip generation, trip chaining, and trip timing represented in the procedure. This is partly due to a lack of theory. Economic theory is often too simplistic to account for the complexity of travel behavior with its multitude of potential behavioral adjustments (e.g., one can change any one or combinations of trip frequency, destinations, modes, routes, trip timing, and linkages). ${ }^{2}$ Attempts have been made to construct travel behavior models that draw on broader theoretical bases (e.g., Bhat 1991; Koppelman and Townsend 1987; Pas and Harvey 1991). Yet many steps need to be taken before these efforts can be reflected in the practice of travel demand forecasting.

Furthermore, determining the effect of added capacity is not at all a trivial task because it is concerned with intricately and dynamically interrelated system components: transportation supply system, land use, accessibility, and travel demand. The transportation supply system

\footnotetext{
1 This is not to say that transportation capacity alone can induce growth in an urban area. The extensive discussions on the subject of transportation investment and urban growth found in the literature (e.g., Bone and Wohl 1959, Levitan 1976) suggest that transportation capacity is just one of the factors that jointly contribute to growth and development (Deakin 1991).

${ }^{2}$ Perhaps the most realistic cases are analyses of the shopping trip frequency and destination choice (e.g., Narula et al. 1983; Thill 1985). But even they are extremely simplistic.
} 
affects land use, as evidenced by land use development that seems to inevitably follow the construction of new facilities. Together, transportation supply system and land use define accessibility. Induced trips represent the effect of accessibility on trip generation. Travel demand, in turn, affects the transportation supply system through the planning process. These interrelationships, with built-in lag time, imply an urban system that may be viewed as a labyrinthine "ecological system". Consequently, an attempt to model one variable (i.e., travel demand) as a function of the rest encounters highly multicollinear explanatory variables, making the identification of each contributing factor's effect impractical.

This paper presents a review of theoretical and empirical results in the literature that shed light on the effect of added transportation capacity. The purpose of the effort is to establish a base from which future research effort can depart. The review of theoretical studies is limited only to those aspects of daily travel behavior for which empirical observations are available. Studies on network assignment and departure time choice are outside the scope of this study. Theories and empirical evidence on the long-term impact of added capacity are also outside the scope, except for a review of disaggregate choice models on household auto ownership.

This paper is organized as follows: In the next section, several theoretical models and paradigms of urban travel behavior are discussed. The following section offers a review of empirical studies that examine the impact of highways on travel and addresses the limitations of the current demand forecasting procedure, while the last section presents conclusions and future research directions.

\section{THEORETICAL APPROACH}

A comprehensive theory of urban travel behavior is difficult to establish, perhaps because travel is such a fundamental element of life. Individuals travel for economic, social, psychological, and physiological reasons. Although some aspects of travel behavior (e.g., travel mode choice) may be well described using theories scattered in these academic disciplines, constructing an embracing theory of urban travel and formulating a system of quantitative models has not yet been accomplished.

Examining the impact of added capacity would require a more fundamental understanding of why people travel. It would also require the accumulation of empirical evidence based on exact measurements of each factor's effect. As a precursor of such an endeavor, the discussions in this section focus on micro-economic formulations of travel behavior, the paradigm of constancy in travel time budgets, evidence offered by what may be called the "ecological approach," the effect of accessibility as a general measure of the generalized cost of travel, and some of the difficulties associated with identifying the effect of generalized travel costs on travel (which is a function of the capacity the supply system offers, the spatial distribution of opportunities, and travel demand).

\subsection{Economic Theory}

The cost of transporting goods and passengers plays a critical role in theories of land use and urban development. Theoretical models have been constructed to explain a firm's decision for locating its plant, a household's choice of where to reside, or a retailer's selection of store locations. For example, a household may be willing to live farther away from the city center and spend more time commuting if that will allow more residential space to be consumed. The rent per unit space then must decrease as the distance from the city center increases. Empirical 
observations often agree with such relations theoretically derived for highly hypothetical and abstract models of urban areas (for a recent review, see Berechman and Small 1988).

A very fundamental relationship in economics is between supply and demand: the demand for a good increases as its price decreases, while supply increases as the price increases; and an equilibrium will be attained where the demand equals the supply, with the good at an equilibrium price. This can be applied to urban travel by viewing transportation as a consumed commodity (e.g., Wohl, 1963). For illustrative simplicity, let the time cost-of-travel be the only cost, and let this cost be proportional to the inverse of the average travel speed in a hypothetical urban area. Then the demand for travel increases as travel speed increases and travel cost decreases. But as demand increases (therefore, as traffic volume increases), speed declines and travel cost increases. The former relationship constitutes a demand curve and the latter a supply curve. The intersection of these two curves indicates an equilibrium volume and speed. An improvement to the roadway infrastructure (increased capacity) would lower the supply curve (a larger volume can be carried at the same speed) and the equilibrium point would shift to the right to a larger equilibrium volume, a higher speed, and a lower cost. The message is quite clear: Added capacity will lead to an increase in travel with the volume added after the improvement representing "travelers diverted from other facilities, those making more frequent trips, those switching from other modes of travel, or those making entirely new trips" (Wohl, 1963, pp. 52-53). This, however, represents a highly simplistic and aggregate approach to travel behavior. People make trips to engage in activities at different locations; the demand for travel is a derived demand and should be treated as such.

In their microeconomic derivation of a gravity model of trip distribution, Niedercorn and Bechdolt (1969) depict trip making as a resource allocation behavior. A visit by a trip maker situated at $\mathrm{i}$ to a destination zone $\mathrm{j}$, is assumed to produce a positive amount of utility, with repeated $T_{i j}$ visits collectively yielding utility, $U_{j}\left(T_{i j}\right)$. Function $U$ is assumed to be strictly concave, i.e., $\left.\mathrm{dU}_{\mathrm{j}}\left(\mathrm{T}_{\mathrm{ij}}\right) / \mathrm{dT}_{\mathrm{ij}}\right)>0$ and $\left.\mathrm{d}^{2} \mathrm{U}_{\mathrm{j}}\left(\mathrm{T}_{\mathrm{ij}}\right) / \mathrm{dT}_{\mathrm{ij}}{ }^{2}\right)<0$ for $0 \leq \mathrm{T}_{\mathrm{ij}}<\infty$. A fixed amount of travel resources, $\mathrm{M}_{\mathrm{i}}$, is allocated to trips to visit available destination zones. With $\mathrm{M}_{\mathrm{i}}$ measured in monetary terms, and the assumption that $\mathrm{U}_{\mathrm{j}}$ can be expressed in terms of a measure of the attractiveness of destination zone $\mathrm{j}, P_{j}$, and function $\mathrm{f}\left(\mathrm{T}_{\mathrm{ij}}\right)$, the optimum frequencies of visits are obtained by:

$$
\begin{gathered}
\operatorname{maximize} U_{i}=\sum U_{j}\left(T_{i j}\right)=\sum P_{j} f\left(T_{i j}\right) \\
\text { subject to } r \sum d_{i j} T_{i j} \leq M_{i},
\end{gathered}
$$

where $d_{i j}$ is the distance between $i$ and $j, r$ is the cost per unit distance of travel and the summation is over all of $\mathrm{j}$. If a logarithmic function is assumed for $\mathrm{f}$, the optimum frequencies to the respective destination zones are found to be:

- directly proportional to $\mathrm{M}_{\mathrm{i}} / \mathrm{r}$,

- directly proportional to $\mathrm{P}_{\mathrm{j}} / \sum \mathrm{P}_{\mathrm{j}}$, and

- inversely proportional to $\mathrm{d}_{\mathrm{ij}}$.

This analytical framework is immediately applicable with $\mathrm{M}_{\mathrm{i}}$ defined to be a travel time budget, i.e., a maximum amount of total travel time that can be expended. Since $U_{j}$ is increasing for $0 \leq \mathrm{T}_{\mathrm{ij}}<\infty$, this budget is always used up when trip frequencies are optimized. Then, improvements in travel speed will always result in additional trips, additional vehicle miles traveled (VMT), and, if improvements are not uniform over the network, shifts in trip distribution. For example, a uniform improvement in travel speed by 
10 percent will result in an increase by 11.1 percent $(=1 / 0.90)$ of both trip frequency and VMT. (Different relationships can be obtained by assuming different functional forms for the utility function; see Niedercorn and Bechdolt 1969.)

Similar approaches are taken by Beckmann and Golob (1972), who examined a wider range of behavioral formulations including:

$$
\text { maximize } U\left(T_{i 1}, \ldots, T_{i j}, \ldots, T_{i n}\right)-\sum C_{i j} T_{i j},
$$

where

$\mathrm{C}_{\mathrm{ij}}$ is the generalized cost of a round trip from $\mathrm{i}$ to $\mathrm{j}$.

In this formulation, the net benefit to a household derived from travel is maximized. Beckmann and Golob also adopt depictions of trip making as a resource allocation behavior and briefly discuss the case where both monetary and time budget constraints exist. ${ }^{3}$ The conclusion of their analysis is similar to those discussed above: Trip frequencies will increase as the generalized cost-of-travel decreases. ${ }^{4}$

\subsection{Travel Time Budgets}

When trip making is viewed as a resource allocation behavior, then the total travel resource that can be allocated becomes a primal driving factor. Zahavi proposes an alternative travel demand forecasting procedure that explicitly incorporates time and monetary budgets for travel. Zahavi's paradigm of constant travel time budgets and the empirical observations on which it is based (Zahavi and Talvitie 1980, Zahavi and Ryan 1980) have led to extensive debates (e.g., Downes and Emmerson 1983; Supernak 1982, 1984; Zahavi 1982; van der Hoorn et al. 1983). Zahavi's approach is one of a few principles of travel behavior that have been developed into operational forecasting systems. Its use has been alluded to recently by Stopher (Applied Management and Planning Group 1990) as a possible approach to accounting for the travel impact of added capacities. A close review of the approach appears to be warranted.

The Unified Mechanism of Travel (UMOT) model is proposed as an alternative to traditional approaches to urban passenger travel and demand-supply relationships (see Zahavi and McLynn 1983). The backbone of the UMOT model is the hypothesis of the constancy in household travel budgets. "The UMOT model maximizes the daily spatial and economic opportunities per household, represented by the daily travel distance, under explicit constraints. The constraints are the daily travel time and money expenditure per traveler and per household, respectively. These travel budgets have been found to display consistent regularities and to be transferable both spatially and over time" (Zahavi and McLynn 1983, p. 137). This formulation of trip making as a travel distance maximization process is based on the viewpoint that travel itself produces utility, therefore, savings in travel time and costs will be used for more travel. It is, however, noted without further

\footnotetext{
3 This work is said to be the basis of Zahavi's UMOT model system discussed next (Zahavi and McLynn 1983).

4 These approaches do not consider the consolidation of several visits to several destinations into one trip chain (e.g., a trip to work and a trip to shop combined to form a chain of work trip, shopping trip, and home trip), or consolidation of several visits made to the same destination into one visit (e.g., one weekly shopping trip instead of seven daily trips). Another weakness is that no attention is given to how a time or monetary budget for travel is established.
} 
clarification that "both the travel time and money budgets are state variables that change during each iteration" (Zahavi and McLynn 1983, p. 138).

These assumptions underlying UMOT yield many interesting insights, e.g., households respond to an increase in auto monetary travel cost, not by reducing the level of auto ownership but by choosing to hold automobiles of lesser quality, or of lower "car factor" values. The car factor represents the quality of the vehicles that tend to be owned by households in each income group, or "the type of car associated with each income group, namely above or below a standard car, where the value of $1 \ldots$ signifies a standard car" (Zahavi and McLynn 1983, p. 144).

At the same time, these assumptions seem to produce counter-intuitive indications. For example, Zahavi and McLynn report that higher income households are able to satisfy their travel needs by increasing vehicle ownership levels, but "low-income households, on the other hand, cannot satisfy the demand for car travel to all their travelers. Furthermore, since the increasing number of travelers have to be satisfied by other modes than car, say buses, all [of] which require travel expenditures, car ownership levels actually decrease with increasing household size" (Zahavi and McLynn 1983, p. 145). Or, "gasoline consumption may increase, not necessarily decrease, at some point along the increases in car unit costs... The reason for this somewhat unexpected result is that decreases in the car factor (namely, increasing the average age of cars) result in increases in gasoline consumption" (Zahavi and McLynn 1983, p. 149). Perhaps the most paradoxical is the result that "a reduction of bus fares... may allow low income travelers to transfer the freed-up bus fares to car travel... conventional wisdom tells us that bus fare reductions should attract car travel to bus travel, while the UMOT model predicts otherwise" (Zahavi and McLynn 1983, p. 151). In other words, when bus fares are reduced, low-income travelers can use the resulting savings for auto travel. While Zahavi and McLynn maintain that this is an example of the Giffen effect with bus trips being an "inferior good," no empirical evidence is offered in support of the result.

It is not difficult to imagine that the UMOT model system is at best controversial. Downes and Emmerson ( 1983) note that "the effects of trip characteristics on trip rates are not fully understood" and present a study that examines the effect of improved travel speeds on the trip length and frequency. They use 1976 large-scale household interview survey results from 12 municipalities of varying populations and sizes. The study separately analyzes a sub-sample of 32,000 individuals who "only traveled internally" within the study areas (Downes and Emmerson 1983, p. 174) and concludes that the total travel expenditure decreases as travel speed increases for those internal travelers, while it increases with speed if external travel is included.

The results thus cast doubt on the assumption of constant travel time expenditure. The study, however, does not explicitly state how the average speed was defined for each traveler. If the average speed is defined as the total distance traveled by a traveler divided by the total time it took (which is suggested by the discussion on p. 176), then this variable is endogenous and the results by Downes and Emmerson could be seriously biased.

Van der Hoorn et al. (1983, p. 156) acknowledge that the UMOT approach is "very appealing to policy makers and researchers because it is conceptually simple and robust, the data requirements are low and the model is easy to compute on a micro computer". However, their effort to implement the model for the Netherlands has led to the identification of several limitations in the model, questionable mode use elasticities with respect to their costs, and a finding that the auto ownership component is "too simplistic" (Van der Hoorn et al. 1983, p. 168). In his comments to van der Hoorn et al. Zahavi notes that most of the limitations are accounted for in the latest version of the UMOT model. 
Supernak (1982) points out the inconsistency that exists among various measures of travel budgets (or expenditures) and cites empirical observations that contradict the hypothesis of constant travel budgets. In particular, Supernak reports that trip rates are "more regular and stable" than travel time budgets, supporting the conventional sequential approach that starts with trip generation analysis.

It is indeed unfortunate that Zahavi passed away before he was able to complete the UMOT model. It is yet to be determined whether the above counter-intuitive indications from the UMOT model are logical consequences of the assumption of constant travel budgets or mere aberrations resulting from a forecasting system yet to be completed.

\subsection{Accessibility and Added Capacity}

An accessibility measure, representing the relative ease of reaching opportunities in an urban area from a specific area within it, may be interpreted as a general indicator of the cost of travel. Then, applying the economic principle discussed earlier, residents in a highaccessibility area should tend to travel more, not necessarily in terms of travel time or cost, but in terms of trip rates or VMT. Theoretically, it is expected that trip generation is positively correlated with accessibility.

Added transportation capacity, whether by means of additional freeway lanes, highoccupancy vehicle (HOV) lanes, or public transit lines, implies increased accessibility in impacted areas. The effect of added capacity, then, can be examined by testing the relationship between accessibility and travel, in particular, trip rates. Note that trip generation analysis, as practiced now, typically does not incorporate accessibility measures. Trip production and attraction are assumed to be functions of socio-demographic and land-use variables, but not accessibility. Added capacity is not viewed as a factor that causes changes in trip generation. ${ }^{5}$

Since accessibility measures will vary within an urban area, cross-sectional data suffice in the test; longitudinal data, although more desirable, may not be necessary. This approach is more attractive than the comparison of changes in travel patterns before and after a capacity improvement. The main advantage is the availability of needed data in practically every metropolitan area. There is no need to wait for a capital project in order to obtain before-and-after observations or to establish a control group in order to capture time effects.

Attempts to establish positive links between accessibility and trip generation, however, have not been successful. The most frequently referenced study is by Nakkash and Grecco (1972). Their results exhibit statistically significant effects of accessibility only on school trip production and attraction; accessibility measures are not significant in most trip generation equations. Taken literally, the results lend support to the current practice of trip generation analysis by showing the absence of capacity effects on trip rates with the only exception being school trips. Before drawing any conclusion, however, it is necessary to review the relationships among the key contributing factors of urban trip making.

\footnotetext{
5 A notable exception is MTCFCAST, a model system developed for the Metropolitan Transportation Commission (MTC). This model system is discussed later in this paper.
} 
Table 1 Correlations among density, relative accessibility, and autos per dwelling unit

\begin{tabular}{llll}
\hline & a. & b. & c. \\
\hline a. Net Residential Density (logarithm) & 1.000 & 0.703 & -0.691 \\
b. Accessibility Ratio (transit to auto) & & 1.000 & -0.652 \\
c. Number of Autos per Dwelling Unit & & & 1.000 \\
\hline
\end{tabular}

Source: Shindler and Ferreri (1967)

\subsection{Ecological Correlations}

Urbanization is a result of the benefit of clustering: "To achieve most of the goals that human beings have, 'cluster' is more efficient than 'scatter' "(Smith 1975, p. 26). Although the preference for isolation may exist, it may be preferable to surrender "isolation or control over space in the interest of conserving transportation resources" (Smith 1975, p. 27). This is especially the case for production due to both internal and external economies of scale. Transportation cost, then, explains the intensity of land use, population density, and rent (land value) that decline with the distance from the urban center. Because the city center represents a concentration of opportunities, accessibility in general decreases with the distance from the city center.

The observation that certain levels of residential density are needed for public transit to be viable (Pushkarev and Zupan 1976) implies that public transit either offers limited service or is not available at all in low density areas. Residents in these areas are then required to have automobiles to gain mobility. This is well supported by empirical observation (e.g., Dunphy 1972; Mogridge 1986). Using data from Portland, OR, and Vancouver, BC, Shindler and Ferreri (1967) derive bivariate correlation coefficients among the logarithm of net residential density, transit-to-auto accessibility ratio, and the number of automobiles per dwelling unit as shown in Table 1.

It is also well established that auto ownership is most significantly associated with transit use. Shindler and Ferreri (1967) summarized that the relationship between auto ownership and transit use "was so strong, that auto ownership dominated all other factors in explaining the trip-making split between auto and transit travel. Thus, for any given level of auto ownership in an area, transit use was, in a sense, predetermined regardless of the quality of service" (Shindler and Ferreri 1967, p. 24). Additional variables that may enter the picture here are household size and income. These variables are correlated positively with auto ownership and negatively with residential density and accessibility ratio. This may be explained in part by the tendency that households with children prefer single family housing and suburban lifestyles. Thus, an urban area exhibits intricate correlations among variables that are closely related to household travel behavior. These correlations, which may be called "ecological correlations", are the results of decisions made by households and firms and actions taken by public agencies over time. ${ }^{6}$

\subsection{Effects of Added Capacity}

A direct consequence of such strong and clear relationships among residential density, household size, income, and auto ownership, is the multicollinearity that exists among

\footnotetext{
${ }^{6}$ However, note that ecological correlations are consequences; they are not causes that will lead to changes in the future.
} 
these variables, which traditionally have been considered to most strongly influence household trip generation. Being defined as a function of land use and inter-zonal travel time variables, accessibility measures are also multicollinear with the other contributing factors. As a result, it is extremely difficult to determine the independent effect of each contributing factor. ${ }^{7}$

Consequently, it has not been possible to produce definitive answers to such seemingly rudimentary questions as: "Does an increase in capacity induce trips?" or "Can we decrease automobile ownership and increase transit use by increasing residential density?"

The problem is further compounded due to the endogeneity of these "explanatory" variables. Although variables representing land use, auto ownership, and accessibility have traditionally been treated as exogenous variables that are determined outside the system, they actually not only feed into each other, but also are influenced by travel demand over time. Residential and commercial land use and transportation networks together define accessibility and travel demand. Travel demand and transportation supply characteristics determine the levels of service available on networks. Levels of service, in turn, lead to the enhancement of network characteristics through planning actions, which lead to further residential and commercial land-use development. As this cycle repeats itself over time, it creates an evolving system in which all pertinent variables are endogenously determined within the system. The effect of capacity increase has not been examined in this dynamic context. ${ }^{8}$

Summarizing the discussion of this section, economic formulations of trip making offer unambiguous indications that added capacity, which implies decreased cost-of-travel, would lead to more trips and VMT. Furthermore, they have shown that travel time, or monetary budgets, play an important role. Travel budgets, or travel expenditures to be more precise, are clearly determined by households, although no models reviewed here attempt to model the process of determining a travel budget endogenously. The most desirable level of travel expenditure of either time or money will vary from household to household or from situation to situation. The notion of forecasting future travel demand based on the assumption that the travel expenditure of a household remains constant over time is not well founded and appears to produce results that cannot be theoretically supported. Then how does travel expenditure, or trip making in general, change in response to changes in capacity and resulting changes in generalized travel costs? No definite answer to this question appears to be available. The discussion here pointed out the multicollinearity among the factors that contribute to trip making, which is a consequence of ecological correlation that prevails in an urban area. In the sections that follow, pieces of empirical evidence are put together to form empirical conclusions on the impact of added capacity.

\footnotetext{
7 The approach frequently taken when multicollinearity is present is to eliminate some of the multicollinear variables to produce a set of relatively independent explanatory variables. It is not surprising if accessibility measures are the first to be eliminated because, unlike household size, car ownership, or income, they are aggregate measures defined for traffic zones. As such, they are subject to measurement errors and exhibit smaller variations (see, e.g., McCarthy 1969; Fleet and Robertson 1968) and are likely to have less significant coefficients associated with them.

8 The problem is even more complex when regional demographic and economic growth is taken into account. This leads to another issue of whether transportation capacity leads to regional growth. As noted earlier, the extensive discussions on this subject found in the literature suggest that transportation capacity is just one of the contributing factors.
} 


\section{IMPACT OF NEW HIGHWAYS}

The literature on the impact of new highways appears to be dominated by cost-benefit analyses of highway investment. For example, a sample of articles in Transportation Research Record includes economic impact analyses by Batchelor et al. (1975), Gaegler et al. (1979), and Mahady and Tsitsos (1981), articles emphasizing property values as a major element in the cost-benefit analysis by Gamble et al. (1974) and Langley (1976), and articles focusing on community values by Ellis (1968) and Falk (1968). Empirical studies of the impact of new roadways on travel behavior, however, are surprisingly few and far between. ${ }^{9}$

A report by U.S. Department of Transportation (1981, p. 22) concludes:

It seems clear from the studies which have been conducted over many years that highway service level improvements do induce increases in VMT. However, the magnitude of induced traffic is thought by some to be quite small and, by others, to be significant in certain circumstances.

On the other hand, Smith and Schoener (1978) maintain:

A frequent statement advanced by transportation professionals is that highway improvements, by inducing travel, create more congestion than they eliminate. Although few data exist to support this statement, it has gained legitimacy by sheer repetition.

This view is repeated in a Research Results Digest issue (Transportation Research Board 1980).

In the next section, available evidence is reviewed to assess the effect of new highways on travel, especially on induced trips.

\subsection{Taxonomies}

Many highways have been built during the periods when urban areas were undergoing demographic and economic growth. Urban growth has been accompanied by new highways, and new highways are sooner or later surrounded by growing suburbs. In this sense, new highways have been synonymous with urban growth and growing travel demand. The first step in the effort to reveal structural relationships between added capacity and travel demand would be to define different elements of the traffic that seemingly fills up a new highway almost immediately.

Zimmermann et al. (1974) propose that traffic on a (new or capacity-improved) highway be classified into:

- Existing traffic

- Development traffic (due to land-use changes)

- Natural growth (demographic and socioeconomic changes)

- Diverted (from other streets or highways)

- Induced (new trips made because of the new highway)

- Transferred (from other modes)

- Shifted (to new destinations).

9 A very recent, notable exception is a study of a new ring road in Amsterdam, The Netherlands, to be presented at the forthcoming 1992 TRB Annual Meeting. Unfortunately, written documents were not available in time for this presentation. [Ed. note: see Kroes et al. (1996)]. 
The last four categories are consequences of a new highway of which induced traffic is a part. Holder and Stover (1972) propose to distinguish between "apparent induced traffic" and "true induced traffic" (read in CSI and JRK, 1979, p. E-1). Similar to Zimmermann et al. Holder and Stover also attribute changes in traffic counts as being due to "cultural traffic (shifts in demographic or socioeconomic characteristics), converted traffic (from other modes), developed traffic (resulting from land-use change), and diverted traffic (from other streets and highways)" (CSI and JRK, 1979, p. E-1). The development traffic and natural growth traffic, as defined by Zimmermann et al., represent increases in trip generation that are accounted for in the land-use model that provides input to the trip generation models in the sequential demand forecasting procedure.

Similarly, diverted traffic, transferred traffic, and shifted traffic are, in principle, accounted for by the trip distribution, modal split, and network assignment phases of the procedure - although actual practice may be less than ideal (see Harvey and Deakin 1991; Applied Management and Planning Group 1990). This leaves induced traffic unaccounted for in the sequential demand forecasting procedure. Also unaccounted for is the effect of a new highway on the temporal distribution of traffic, which is not considered in these classification schemes of traffic.

The review of empirical evidence in the literature presented below indicates that new highways do have an impact on VMT, presumably due to a large extent to shifted traffic. This impact is well represented by the demand forecasting procedure. The impact of a new facility on induced traffic, however, is not evident.

\subsection{IImpact on VMT}

The average trip length appears to increase with the construction of new highways. Voorhees et al. (1962) cite that the average work trip length in Baltimore increased from 2.6 miles in 1926 to 4 miles in 1946, and to over 5 miles as of the writing of the paper.

Bellomo et al. (1970) also note similar historical increases in trip lengths. For example, "In Detroit the mean auto driver work trip length in miles increased by 18 percent as the area increased in population by 14 percent, and the average speed of network increased by 12 percent between 1953 and 1965" (p. 1). Presumably, this is due to a large extent to the geographical and demographic expansion of the area, leading to substantial development and natural growth traffic and, probably to a lesser extent, to shifted traffic.

Voorhees et al. (1966) offer quantitative indications of the effect of population and network speed on trip length. Based on aggregate data (average trip duration, etc.) from 23 cities, the following model was developed:

$$
L=0.003 P^{0.20} S^{1.49},
$$

where:

$\mathrm{L}=$ the average trip length in miles

$\mathrm{P}=$ the urban area population

$\mathrm{S}=$ the average network speed in miles per hour.

The positive effect of network speed on trip length is evident. The effects of the "physical structure of an urban area" on the trip duration and distance are also noted in the study. The distribution of opportunities is not considered in the study.

Accounting for the size and physical structure of an urban area, the network speed, and socioeconomic factors are considered crucial in forecasting future trip length (Voorhees 
et al. 1966, p. 36). Based largely on simulation results, the effects of network speed are summarized as:

(a) change in the average trip length (miles) for uniform density cities will probably be directly proportional to the square root of changes in network speed, and,

(b) change in the average trip length (minutes) will probably be inversely proportional to the square root of changes in network speed.

Experience, however, has shown that peak hour speeds have not greatly changed in large metropolitan areas (Voorhees et al. 1966, p. 36). Then, an addition of capacity, which would lead to a higher highway speed, would also lead to an increase in VMT.

The results reported by Frye (1963) also indicate that a capacity increase has a direct impact on traffic beyond development and natural growth traffic. The opening of the Congress Expressway in a 16 square-mile area in the western suburbs of Chicago led to an increase in the total VMT in the area by 21 percent between 1959 (before opening) and 1961. An increase of 7 percent could be expected in the area due to natural growth. Frye's findings are summarized in U.S. Dept. of Transportation (1981, pp. 20-21) as: "About half the total increase (10.5 percent) was due to diversion of traffic from areas outside the study area. The other 3.5 percent is attributed to induced traffic (i.e., new or longer trips) and adverse travel (the extra VMT generated by travelers going out of their way to use the new facility)...."10

\subsection{Induced Trips}

Unlike the other types of traffic on a new highway, induced traffic must be captured in the trip generation phase of the sequential forecasting procedure. Trip generation models typically use demographic and socioeconomic variables for residential trip generation (e.g., household size and auto ownership) and land-use variables (e.g., zonal employment, retail and floor area) for non-residential trip generation. It is not common practice to use variables that represent transportation supply characteristics. In fact, the current practice of trip generation analysis appears to be based on the premise that there exist constant household trip rates that do not change over time, do not vary within or across metropolitan areas, and are unaffected by the levels of service on transportation networks. Typical examples can be found in the Institute of Transportation Engineers (ITE) trip rates (ITE 1979), "quick response" demand forecasting procedures, and computer program packages (e.g., Sosslau et al. 1978a, b).

Contrary empirical evidence does exist. For example, Goulias et al. (1990), in their analysis of 1980 Detroit home interview travel survey results, find that dummy variables representing the county of residence are significant in many of the household trip generation models by purpose estimated in the study. Yet no compelling indicator of tripinducing effect of added capacity appears to be offered in the studies reviewed below.

As noted earlier, Nakkash and Grecco (1972) present formal statistical tests of the significance of accessibility measures in trip generation equations. They argue, "Conceptually, there is not a strong basis for assuming that trip making is independent of the transportation system" (p. 99). The issue addressed here is precisely that of induced trips in the narrow sense as defined by Zimmermann et al. (1974). If, as economic theory implies, a decrease in the generalized cost of travel leads to an increase in trip making, then households residing in zones with high accessibility would exhibit higher trip rates.

10 The term "induced traffic" is used in a broader sense to include both induced and shifted traffic as defined by Zimmermann et al. (1974). 
Nakkash and Grecco examine this hypothesis by testing the statistical significance of accessibility measures in trip generation models.

The method used is straightforward. A "relative accessibility measure" is defined by trip purpose using destination "mass" terms and friction factors (based on auto travel times; Nakkash and Grecco 1972, p. 102) and normalizing it as follows:

$$
\begin{gathered}
A_{i k(l)}=\sum_{j=1}^{n} S_{j k} F_{i j(l)} \\
R A_{i k(l)}=A_{i k(l)} / \sum_{i^{\prime}=1}^{n} A_{i^{\prime} k(l)},
\end{gathered}
$$

where:

$\mathrm{S}_{\mathrm{jk}}=$ the size of activity $\mathrm{k}$ in zone $\mathrm{j}$,

$\mathrm{F}_{\mathrm{ij}(\mathrm{l})}=$ the friction factor corresponding to the travel time from zone $\mathrm{i}$ to zone $\mathrm{j}$ for purpose 1,

$\mathrm{A}_{\mathrm{ik}(\mathrm{l})}=$ the accessibility of zone $\mathrm{i}$ to activity $\mathrm{k}$ for purpose 1 ,

$\mathrm{RA}_{\mathrm{ik}(\mathrm{l})}=$ the relative accessibility.

This measure is introduced into trip production and attraction models (by purpose) that were developed in the Indianapolis Regional Transportation and Development Study (altogether 13 models are defined). The models are estimated with and without stratification, which divided the study area into central and non-central areas (the former comprises 105 zones out of the 395 zones in the study area, Nakkash and Grecco 1972, p. 103).

The results of this analysis are, unfortunately, inconclusive. Presumably due to the multicollinearity problem discussed earlier, Nakkash and Grecco report that often "no satisfactory models were developed," or "models were developed but no statistical testing was possible" (p. 107). Only two pairs of trip production models and two pairs of trip attraction models were successfully estimated that can be legitimately used to test the significance of the accessibility measure. Of these, only one production model and one attraction model (both for home-based school trips) offer significant results. (The results are quite counter-intuitive as school trips are of mandatory nature and should be least influenced by accessibility. This may have been caused by the practice of excluding nonmotorized trips from trip diaries that was prevalent at the time their data were collected.)

It is entirely possible that trip generation is in fact largely unaffected by accessibility, as suggested by the Nakkash and Grecco study. However, it is also possible that, as noted repeatedly in this paper, multicollinearity among the explanatory variables may have led to the insignificant accessibility coefficients. The models may have been subject to specification errors; introducing the accessibility measure as a linear additive term may not have been appropriate. Accessibility measures are another potential problem. These zonal variables tend to exhibit small variations across zones and erroneously represent the true accessibility available to each household. Finally, the aggregate, zone-based analysis may have been too insensitive to detect the effect of accessibility.

Kannel and Heathington (1974) examine a panel of households interviewed in both 1964 and 1971. The same panel of households is used in their 1973 study of the stability in trip generation analysis. The objective of this 1974 study was to examine the hypothesis that "trip production from households is affected by the accessibility of the household to major activity centers within the urban area" (p. 78). The accessibility measures developed by Nakkash (see Nakkash and Grecco 1972) are used in the study. 
Kannel and Heathington use causal models to examine cause-effect relationships among several endogenous variables, including accessibility, car ownership, and mobility. The indicator of mobility is the number of home-based (presumably motorized) trips. Two alternative model structures are examined (each structure is applied to the 1964 and 1971 data and lead to very stable sets of coefficients). In the first structure, accessibility affects both car ownership and trip generation negatively. In the second model, which is preferred to the first by the authors, the direct link from accessibility to trip generation is eliminated. Thus, accessibility affects mobility, but only indirectly, through car ownership.

Smith and Schoener (1978) examine the impact of highway I-95 based on "data from origin-destination travel surveys conducted by the Rhode Island Department of Transportation in Providence for 1961 (before construction of I-95) and 1971 (after I-95)” (p. 152). Households are cross-classified according to household size and car ownership. The dependent variables are VMT per household, vehicle hours of travel (VHT) per household, and car driver trips per household. Repeated cross-sectional data are used to address these issues. The 1961 sample contains 11,467 households, but the 1971 sample contains only 855. The study concentrates on vehicular trips: "all trips that were not car driver trips" were eliminated from the data set (p. 154). The study area is divided into two areas: the portion inside the influence of the new highway and the portion outside it.

Smith and Schoener (1978, p. 153) correctly point out that: "Many previous studies have shown that a correlation exists between aggregate highway supply per capita and VKMT per capita. The existence of such a correlation, however, does not guarantee the existence of a causal relationship between the two variables". Their analysis, based on household data, accounts for this problem and offers extremely interesting statistics. They conclude (p. 152):

The comparison of the resulting matrices revealed that the highway did not increase trips or VHT, but it did increase VKMT. This allows the tentative conclusion that travelers increase their VKMT until they use up a given amount of travel time. This conclusion supports the standard system-insensitive approach to trip generation as well as the use of travel time as an impedance in trip distribution.

The study, however, is subject to limitations. First, the sample size for the "after" period is extremely small, probably producing the tendency of accepting null hypotheses of no change. Second, the method used to test the statistical significance of change is less than ideal. Instead of examining the number of significant pair-wise $t$-statistics in before-andafter cross-classification tables, the analysis of variance should have been used.

The concurrent processes of the proliferation of automotive transportation and the decline of urban public transit are well documented by aggregate historical data. The impacts of individual highway projects on transit use are less frequently documented. An interesting exception is a study by Richards and Beimborn (1973) which, based on longitudinal transit ridership records before and after the opening of a highway route, indicates that transit ridership began declining before the highway opening due to residential and commercial relocation, and that the opening itself had only a limited impact on ridership.

The very question of induced traffic is addressed in NCHRP Project 8-19 (CSI and JHK 1979 and TRB 1980). The study is admittedly inconclusive, reflecting the complex nature of trip making, the presence of a wide range of contributing factors, and the resulting difficulties associated with its investigation. Several observations are made in the study. Whether person trips will increase or not is said to depend on the characteristics of the transportation system, such as the reduction of off-peak travel times and costs or the level of congestion before the system change (p. 2-5). "The increase in person trips produced by 
a supply increase may or may not result in an increase in the number of vehicle miles traveled, depending upon the nature of the supply change" (p. 2-6). VMT may decrease if the supply change decreases the distance between prominent origins and destinations or if it encourages multiple occupancy vehicles.

Importantly, "a congested facility generally reflects the presence of unsatisfied or latent demand for trip making that may be satisfied if travel conditions are improved by the construction of new transportation facilities" (p. 2-5). It is noted that non-work trips are more sensitive to supply characteristics, and "the supply change must affect the off-peak travel conditions within the corridor" to have impact on the volume of person trips (p. 2 5). These and a number of other observations made in the report suggest difficulties involved in stating the effect of added capacity in general terms. Whether a capacity addition leads to induced trips or not needs to be determined case by case while considering all the supply characteristics and other contributing factors.

\section{CONCLUSIONS}

Assessing the impact of added capacity is a complex task because of the intricate causal relationships among transportation supply, land use, accessibility, and travel demand. The resulting simultaneity and endogeneity make the use of complex analytical methods inevitable. It is unreasonable to expect that simplistic analyses based on limited data bases will properly address the issue.

At the same time, changes in travel demand are difficult and time-consuming to measure precisely. Although carefully designed evaluation studies may offer valuable insights, the case-specific nature of impacts as discussed in CSI and JHK (1979) suggest that generalization of their results may be difficult.

One conclusion to be drawn from this literature review is that only limited utilization has been made of existing travel survey results. Only a few studies have used accessibility measures, while no studies have attempted to examine the interaction between land use and travel. It is quite likely that this is due to the unavailability of suitable data, despite the many origin-destination surveys.

Traditional origin-destination surveys have been conducted in practically every metropolitan area, quite often at up to three time points that are approximately 10 years apart. Usually, metropolitan planning organizations (MPOs) prepare network and land use data that accompany origin-destination trip records. These data files, however, do not seem to be well archived, well documented, or easily available for research purposes. If complete trip, network, and land-use data sets can be made available from selected metropolitan areas of different sizes and densities, they will form a powerful database that will extend beyond the many limitations discussed in this study. The use of existing origindestination data appears to be a very cost-effective and expeditious approach in addressing the added capacity issue. This and other points are itemized in the following tentative summary of this study:

- There is no empirical indication that added capacity generates a significant volume of induced traffic.

- The standard sequential procedure is capable of forecasting diverted, transferred, and shifted traffic.

- Abbreviated application of the procedure, unwarranted attempts to transfer models and extrapolation of the models to inapplicable options are unfortunately present. 
- A better understanding of the trip timing decision is necessary, especially for non-work trips.

- A better understanding of trip chaining behavior is also needed.

- Impacts on car ownership, residential and job location choice, and land use need to be better understood and incorporated into the forecasting procedure.

- Existing data can be better used with more elaborate statistical methods to test behavioral theories.

- Existing data can be used in multi-regional and multi-period comparative analyses of trip timing decisions, trip chaining behavior, and the issue of suppressed trips.

- Likewise, existing data can be used to examine the effect of congestion on mode and destination choice. Improving the conventional forecasting procedure can be best achieved through analysis of cross-sectional data, because dynamic models derived from longitudinal (especially panel) data may not be compatible with cross-sectional models.

- More widespread use of panel surveys is encouraged.

\section{References}

Applied Management \& Planning Group, Traffic Congestion and Capacity Increases. Prepared for Sierra Club Legal Defense Fund, Inc., and Citizens for a Better Environment, 1990.

T.J. Batchelor, K.C. Sinha, and A. Chatterjee. Benefit-Cost Analysis of the Milwaukee Freeway System. Transportation Research Record, 550, pp. 35-47, 1975.

M.J. Beckmann and T.F. Golob. A Critique of Entropy and Gravity in Travel Forecasting. Traffic Flow and Transportation, (G.F. Newell, ed.), American Elsevier, New York, pp. 109-117, 1972.

S.J. Bellomo, R.B. Dial, and A.M. Voorhees. Factors, Trends, and Guidelines Related to Trip Length. National Cooperative Highway Research Program Report 89. Highway Research Board, Washington, D.C., 1970.

J. Berechman and K.A. Small. Modeling Land Use and Transportation: An Interpretive Review for Growth Areas. Environment and Planning A, Vol. 20 No. 10, pp. 1285-1309, 1988.

C.R. Bhat. "Toward a Model of Activity Program Generation". Unpublished Ph.D. dissertation, Department of Civil Engineering, Northwestern University, Evanston, IL, 1991.

A.J. Bone and M. Wohl. Massachusetts Route 128 Impact Study. Highway Research Board Bulletin, No. 227, pp. 21-49, 1959.

Cambridge Systematics, Inc. and JHK \& Associates. The Relationship of Changes in Urban Highway Supply to Vehicle Miles of Travel. Draft Final Report, National Cooperative Highway Research Program, Project 8-19, Transportation Research Board, Washington, D.C., March 1979.

E.A. Deakin. Jobs, Housing, and Transportation: Theory and Evidence on Interactions Between Land Use and Transportation. Transportation, Urban Form, and the Environment, Special Report 231, Highway Research Board, Washington, D.C., pp. 25-42, 1991.

J.D. Downes and P. Emmerson. Do Higher Speeds Increase Travel or Save Time? In Transportation and Stagnation: Challenges for Planning and Research, (P.H.L. Bovy, ed.), Vol. 1, Proceedings of the 10th Transportation Planning Research Colloquium, Colloquium Vervoersplanologisch Speurwerg, Delft, The Netherlands, pp. 171-187, 1983.

R.T. Dunphy. Transit Accessibility as a Determinant of Automobile Ownership. Highway Research Record, 472, pp. 63-71, 1972.

R.H. Ellis. Toward Measurement of the Community Consequences of Urban Freeways. Highway Research Record, 229, pp. 38-52, 1968.

E.L. Falk. Measurement of Community Values: The Spokane Experiment. Highway Research Record, 229, pp. 53-64, 1968.

C.R. Fleet and S.R. Robertson. Trip Generation in the Transportation Planning Process. Highway Research Record, 240, pp. 11-27,1968.

F. F. Frye. Effects of an Expressway on the Distribution of Traffic and Accidents. Highway Research Record, 21, pp. 90-105, 1963. 
A.M. Gaegler, J.W. March, and P. Weiner. Dynamic Social and Economic Effects of the Connecticut Turnpike. Transportation Research Record, 716, pp. 28-32, 1979.

H.B. Gamble, O.H. Sauedender, and D.J. Langley. Adverse and Beneficial Effects of Highways on Residential Property Values. Transportation Research Record, 508, pp. 37-48,1974.

K.G. Goulias, R.M. Pendyala, and R. Kitamura. Practical Method for the Estimation of Trip Generation and Trip Chaining. Transportation Research Record, 1285, pp. 47-56, 1990.

G. Harvey and E. Deakin. Toward Improved Regional Transportation Modeling Practice. A paper prepared for the National Association of Regional Councils, 1991.

Institute of Transportation Engineers. Trip Generation. Second edition, ITE Informational Report, 1979.

E.J. Kannel and K.W. Heathington. Temporal Stability of Trip Generation Relations. Highway Research Record, 472, pp. 17-27, 1973.

E.J. Kannel and K.W. Heathington. Structural Model for Evaluating Urban Travel Relationships. Transportation Research Record, 526, pp. 73-82, 1974.

F.S. Koppelman and T.A. Townsend. Task Allocation among Household Members: Theory and Analysis. Paper presented at the Seventh International Conference on Travel Behavior, Aix-en-Provence, France, October 1987.

E. Kroes, A. Daly, H. Gunn, and T. van der Hoorn. The opening of the Amsterdam Ring Road: A case study on short-term effects of removing a bottleneck. Transportation, 23(1), pp. 71-82, 1996.

C.J. Langley, Jr. Time-Series Effects of a Limited-Access Highway on Residential Property Values. Transportation Research Record, 583, pp. 73-82, 1976.

D. Levitan. Massachusetts Route 128: A Non-emulative Enigma. Transportation Research Record, 583, pp. 45-54, 1976.

F.X. Mahady and D.C. Tsitsos. Economic Impact of I-78 in Allentown, Pennsylvania. Transportation Research Record, 812, pp. 7-8, 1981.

M.E. McCarthy. Multiple-Regression Analysis of Household Trip Generation - A Critique. Highway Research Record, 297, pp. 31-43,1969.

M.J.H. Mogridge. If London Is More Spread Out Than Paris, Why Don't Londoners Travel More Than Parisians? Transportation, 13, pp. 85-104, 1986.

T.Z. Nakkash. and W.L. Grecco. Activity-Accessibility Models of Trip Generation. Highway Research Record, 392, pp. 98-110, 1972.

S. Narula, M. Harwitz, and B. Lentnek. Where Shall We Shop Today? A Theory of Multiple-Stop, MultiplePurpose Shopping Trips. Papers of the Regional Science Association, 53, pp. 159-173,1983.

J.H. Niedercorn and B.V. Bechdolt. An Economic Derivation of the "Gravity Law" of Spatial Interaction. Journal of Regional Science, 9(2), 273-282, 1969.

E.I. Pas and A.S. Harvey. Time Use Research and Travel Demand Analysis and Modeling. Paper presented at the Sixth International Conference on Travel Behavior, Quebec City, Quebec, Canada, May, 1991.

B.S. Pushkarev and J.M. Zupan. Where Transit Works: Urban Densities for Public Transportation. Regional Plan News, No. 99, August 1976.

C.W. Richards and E.A. Beimborn. Freeway Development Effects Upon Adjacent Transit Usage. Transportation Engineering Journal. 99(TE3), pp. 435-448, August 1973.

A.B. Sosslau, A.B. Hassam, M.M. Carter, and G.V. Wickstrom. Quick-Response Urban Travel Estimation Techniques and Transferable Parameters, User's Guide. National Cooperative Highway Research Program Report 187, Transportation Research Board, Washington, D.C., 1978a.

A.B. Sosslau, A.B. Hassam, M.M. Carter, and G.V. Wickstrom. Travel Estimation Procedures for Quick Response to Urban Policy Issues. National Cooperative Highway Research Program Report 186, Transportation Research Board, Washington, D.C., 1978b.

R. Shindler and M.G. Ferrari. Auto Ownership as Affected by Transportation System Alternatives. Traffic Engineering, pp. 24-28, October 1967.

M.E. Smith and G.E. Schoener. Testing for Significant Induced Trip Making and Travel in Providence, Rhode Island. Transportation Research Record, 673, pp. 152-57, 1978.

W.F. Smith. Urban Development: The Process and the Problems. University of California Press, Berkeley, CA. 1975.

J. Supernak. Travel-time Budget: A Critique. Transportation Research Record, 879, pp. 15-25 (references on pp. 27-28), 1982.

J. Supernak. Travel Regularities and Their Interpretations: A Discussion Paper. Transportation Research Record, 987, pp. 48-56, 1984.

J.C. Thill. Demand in Space and Multipurpose Shopping: A Theoretical Approach. Geographical Analysis, 17, pp. 114-129, 1985. 
Transportation Research Board. The Vehicle Miles of Travel - Urban Highway Supply Relationship. Research Results Digest, National Cooperative Highway Research Program Digest, 127, p. 7, December 1980.

U.S. Department of Transportation. The Costs and Effectiveness of Transportation Control Measures in Achieving Air Quality Goals. Washington, D.C., August 1981.

A.I.J.M. van der Hoorn, W. van Harreveld, J. Vogelaar, and M.J.M. van der VIist. The Application of UMOT in the Netherlands. In P.H.L. Bovy (ed.), Transportation and Stagnation: Challenges for Planning and Research, Vol. 1. Proceedings of the 10th Transportation Planning Colloquium, Colloquium Vervoersplanologisch Speurwerg, Delft, the Netherlands, pp. 155-170, 1983.

A.M. Voorhees, C.F. Barnes, and F.E. Coleman. Traffic Pattern and Land Use Alternatives. Highway Research Board Bulletin, No. 347, pp. 1-9, 1962.

A.M. Voorhees, S.J. Bellomo, J.L. Schofer, and D.E. Cleveland. Factors in Work Trip Length. Highway Research Record, 141, pp. 24-46, 1966.

M. Wohl. Demand, Cost, Price, and Capacity Relationships Applied to Travel Forecasting. Highway Research Record, 38, pp. 40-54, 1963.

Y. Zahavi. Discussion on "Travel-time Budget: A Critique". Transportation Research Record, 879, pp. 2557, 1982.

Y. Zahavi and J.M. McLynn. Travel Choices under Changing Constraints as Predicted by the UMOT Model. In P.H.L. Bovy (ed.), Transportation and Stagnation: Challenges for Planning and Research, Vol. I, Proceedings of the 10th Transportation Planning Research Colloquium, Colloquium Vervoersplanologisch Speurwerg, Delft, the Netherlands, pp. 137-154, 1983.

Y. Zahavi and J.M. Ryan. Stability of Travel Components over Time. Transportation Research Record, 750, pp. 19-26, 1980.

Y. Zahavi and A. Talvitie. Regularities in Travel Time and Money Expenditures. Transportation Research Record, 750, pp. 13-19,1980.

S. Zimmermann, M. West, and T. Kozlowski. Urban Highways as Traffic Generators. U.S. Department of Transportation, Federal Highway Administration, Urban Planning Division, Washington, D.C., p. 29, August 1974. 